\title{
The Blue-Blood Porcine Chest Wall: A Novel Microsurgery Training Simulator for Internal Mammary Vessel Dissection and Anastomosis
}

\author{
Weifeng Zeng, MD ${ }^{1, *}$ Kirsten A. Gunderson, BS ${ }^{1, *}$ Ruston J. Sanchez, MD ${ }^{1}$ Nicholas J. Albano, MD ${ }^{1}$ \\ Zeeda H. Nkana, BS ${ }^{1}$ Kishan M. Thadikonda, $\mathrm{MD}^{1}$ Aaron M. Dingle, $\mathrm{PhD}^{1} \quad$ Samuel O. Poore, MD, $\mathrm{PhD}^{1}$ (1) \\ ${ }^{1}$ Division of Plastic Surgery, University of Wisconsin School of \\ Medicine and Public Health, Madison, Wisconsin \\ Address for correspondence Samuel O. Poore, MD, PhD, Division of \\ Plastic Surgery, University of Wisconsin School of Medicine and Public \\ Health, 600 Highland Avenue, CSC G5/347, Madison, WI 53792 \\ J Reconstr Microsurg 2021;37:353-356. \\ (e-mail: poore@surgery.wisc.edu).
}

\begin{abstract}
Keywords

- surgical simulation

- surgery education

- pig model

Background Preparation of the internal mammary artery (IMA) is a critical step in autologous breast reconstruction. Intraoperatively, there is limited opportunity for residents to practice this skill. Porcine models provide highly realistic simulation for vascular surgery; however, use of live laboratory pigs is expensive, inconvenient, and offers limited opportunity for repetitive training. We aimed to develop an inexpensive and effective training model for IMA preparation. This article describes creation of a novel microsurgical model using cadaveric chest walls of Wisconsin Miniature Swine embedded in a modified mannequin thorax and augmented with a blue-blood perfusion system.

Methods Anatomic comparison: five porcine chest walls were dissected, and various anatomic measurements were made for anatomic comparison to existing human data in the literature. Model assembly: the chest wall is prepared by cannulating the proximal and distal ends of the internal mammary vessels with angiocatheters, which are then connected to the blue-blood perfusion system. The model is assembled in four layers including: (1) a mannequin thorax with a window removed to expose the first to fourth intercostal spaces, bilaterally, (2) a layer of foam simulating fat, (3) the perfused pig chest wall, and (4) a second mannequin shell placed posteriorly for support.

Results The porcine chest walls are similar to humans with regards to vessel size and location. This model can be assembled quickly, with a one-time approximate cost of $\$ 55.00$, and allows for six training sessions per specimen. The model allows residents to practice the key steps of IMA preparation including dissection, elevation of perichondria, and vascular anastomosis while working at a depth that closely simulates the human thorax. Continuous blue-blood perfusion provides immediate feedback on anastomosis quality.

Conclusion Overall, this novel model can provide inexpensive and realistic simulation of internal mammary vessel preparation and anastomosis.
\end{abstract}

These authors contributed equally to this work.

received

May 7, 2020

accepted

August 15, 2020

published online

September 21, 2020 (c) 2020. Thieme. All rights reserved.

Thieme Medical Publishers, Inc.,

333 Seventh Avenue, 18th Floor,

New York, NY 10001, USA
DOI https://doi.org/

10.1055/s-0040-1716859.

ISSN $0743-684 \mathrm{X}$ 
Breast reconstruction is one of the most common reconstructive procedures performed by plastic surgeons worldwide, ${ }^{1}$ with reconstruction using autologous free tissue transfer as the procedure of choice for an increasing number of breast cancer patients. ${ }^{2}$ The internal mammary vessels are the primary recipient vessels for these operations., ${ }^{3,4}$

Appropriate preparation of the internal mammary artery (IMA) and internal mammary vein (IMV) is a critical step of this procedure. Vessel damage can result in failure of the intended reconstruction and operating on the chest wall poses a risk of other complications including pneumothorax. ${ }^{5}$ Given the technical complexity of chest vessel exposure and the concomitant risk of untoward outcomes, the stress of learning the technique in the operating room (OR) is amplified for both the teacher and the learner, even in a controlled environment under supervision.

Existing high-fidelity models utilized in surgical education, such as the blue-blood perfused chicken thigh model, provide realistic simulation for microvascular anastomosis training, ${ }^{6}$ but there are no simulators for practicing appropriate approach to isolating the internal mammary vessels including dissection, rib excision, and vessel preparation. All of these are key aspects of the procedure that residents and fellows must learn to perform. Although live pig models provide more authentic simulation for these skills, they are inconvenient, prohibitively expensive to maintain, and demand a veterinary anesthesiologist for training sessions. Given this, our aim was to create a simple, inexpensive, and realistic model for resident training of IMA dissection and anastomosis.

\section{Methods}

\section{Anatomic Comparison}

Chest walls from adult Wisconsin Miniature Swine were harvested at the completion of other studies at our institution. Five chest walls were dissected for anatomic comparison with existing human data. Rib width, intercostal space (ICS) width, IMA and IMV diameters, distance from lateral sternal border to IMV, and distance from costochondral junction to IMA were measured. Observational comparisons between the pig and humans were also made. A dissected porcine thorax is shown in -Fig. 1 .

\section{Materials}

The materials used for the simulator are inexpensive and easy to obtain. Items needed include cadaveric porcine chest wall (obtained at no cost), two plastic mannequin torso shells (SSWBasics Male Molded Shirt Form, Amazon), $12 \times 12 \times 1$ in layer of multipurpose foam (Future Foam, Home Depot), and two rubber bands. This model is enhanced with the addition of a blue-blood perfusion system, previously utilized in a chicken thigh model for microsurgical training. ${ }^{6,7}$ Standard surgical instruments can be used.

\section{Model Assembly}

Once harvested, chest walls are frozen for storage and thawed for use without disturbance to anatomy or reduction in model quality. Release of the sternoclavicular joint allows the chest

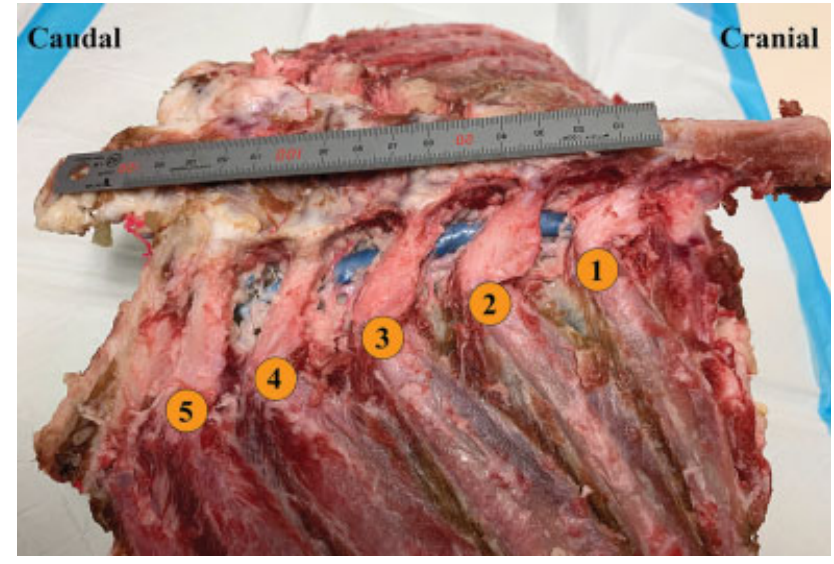

Fig. 1 Porcine chest wall dissected to show blue-blood perfused internal mammary vessels coursing deep to the ribs.

wall to lay flat in a position more analogous to humans. The blue-blood system is set up to perfuse the IMA and IMV during training sessions as previously described. ${ }^{7}$ The model is assembled in four layers. A plastic mannequin shell comprises the first layer and provides rigidity to the model. The perfused chest wall is placed as the second layer. A layer of upholstery foam, mimicking human subcutaneous fat, is situated on top of the chest wall and adds realistic depth. The second mannequin shell is placed as the final layer. An elastic band is placed around all layers at the neck and waist for stabilization. Two holes are made near the neck of the bottom mannequin shell and the sternum of the top mannequin shell for inflow and outflow tubing of the perfusion system to pass. The fully assembled model is shown in - Fig. 2.

\section{Results}

This model can be assembled quickly with a low, one-time cost of approximately $\$ 55.00$. Anatomically, porcine chest walls are similar to human chest walls, with suitable likeness in vessel diameter and location. A detailed comparison of model anatomic measurements with existing human data are shown in - Table 1. ${ }^{8,9}$ We found that pig ribs are slightly flatter, wider,

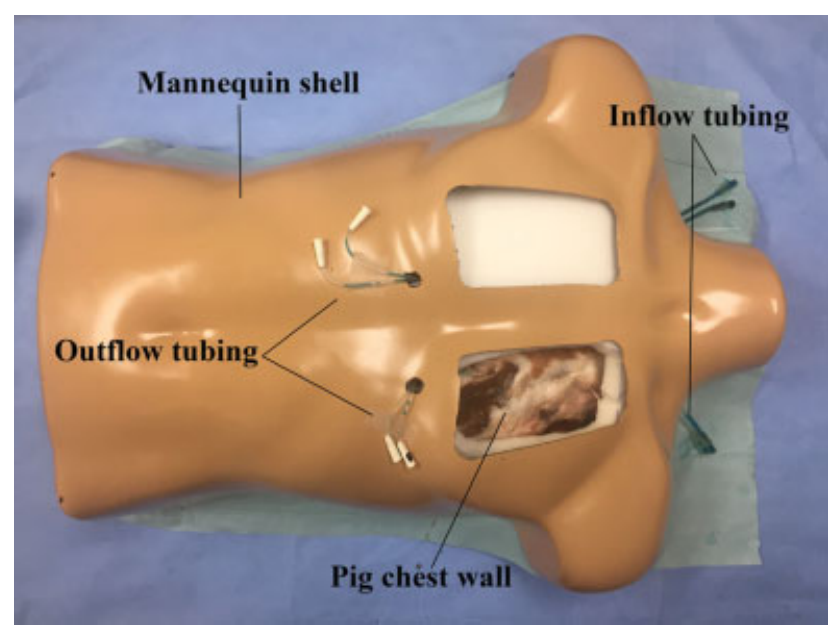

Fig. 2 Fully assembled internal mammary artery training model. 
Table 1 Comparison of pig and human chest wall measurements

\begin{tabular}{|c|c|c|c|c|c|c|c|c|c|c|c|c|}
\hline & \multicolumn{6}{|c|}{ Pig bilateral averages (mm) } & \multicolumn{6}{|c|}{ Human bilateral averages $(\mathrm{mm})^{8,9}$} \\
\hline & $\begin{array}{l}\text { Rib } \\
\text { width }\end{array}$ & $\begin{array}{l}\text { ICS } \\
\text { width }\end{array}$ & $\begin{array}{l}\text { IMA } \\
\text { diameter }\end{array}$ & $\begin{array}{l}\text { IMV } \\
\text { diameter }\end{array}$ & $\begin{array}{l}\text { Sternal } \\
\text { border } \\
\text { to IMV } \\
\text { distance }\end{array}$ & $\begin{array}{l}\text { Costochondral } \\
\text { Junction } \\
\text { to IMA } \\
\text { distance }\end{array}$ & $\begin{array}{l}\text { Rib } \\
\text { width }\end{array}$ & $\begin{array}{l}\text { ICS } \\
\text { width }\end{array}$ & $\begin{array}{l}\text { IMA } \\
\text { diameter }\end{array}$ & $\begin{array}{l}\text { IMV } \\
\text { diameter }\end{array}$ & $\begin{array}{l}\text { Sternal } \\
\text { border } \\
\text { to IMV } \\
\text { distance }\end{array}$ & $\begin{array}{l}\text { Costochondral } \\
\text { junction to } \\
\text { IMA distance }\end{array}$ \\
\hline Second & 15.3 & 12.8 & 3.9 & 5.8 & 5.3 & 12.1 & 11 & 17.5 & 3.0 & 3.3 & 6.1 & 12.8 \\
\hline Third & 16.6 & 12.3 & 3.8 & 5.4 & 5.3 & 16.9 & 12.6 & 14.1 & 2.8 & 3.0 & 9.0 & 24.8 \\
\hline Fourth & 16.3 & 8.8 & 3.4 & 5.1 & 1.9 & 24.1 & 12.8 & 9.8 & 2.5 & 2.6 & 10.5 & 33.3 \\
\hline
\end{tabular}

Abbreviations: ICS, intercostal space; IMA, internal mammary artery; IMV, internal mammary vein.

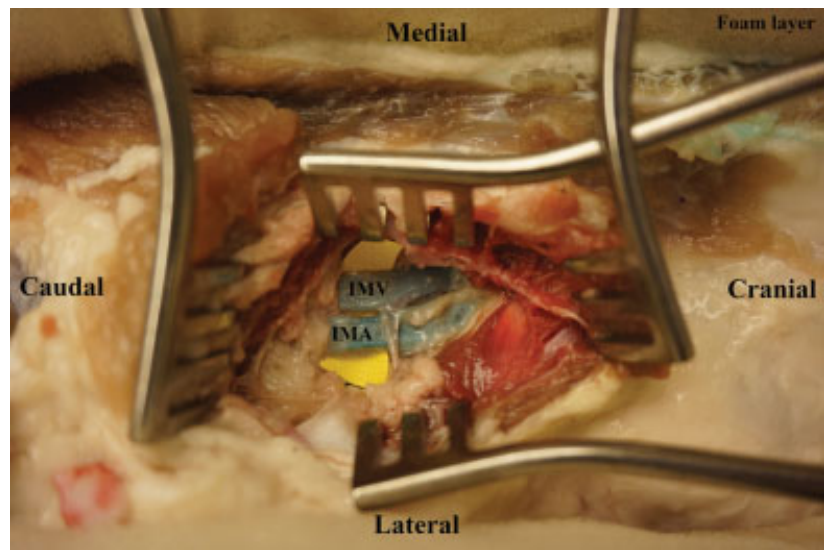

Fig. 3 Image taken during resident training session after dissection, rib excision, and identification of internal mammary vessels.

and have a steeper costochondral angle than human ribs. Additionally, the porcine sternum widens caudally such that it overlies the IMA and IMV at the level of the fifth and sixth ribs. Based on these data and experience, the most realistic simulation can be performed at the second, third, and fourth ICSs. Once assembled, the depth from mid-sternum to internal mammary vessels is approximately $5 \mathrm{~cm}$. An image from a training session after identification of these vessels is shown in -Fig. 3. Training on this model is analogous to performing these steps in the OR ( $\mathbf{- V i d e o} \mathbf{1}$ ).

\section{Video 1}

Narrated video captured through a surgical microscope showing a resident training session on the novel blue-blood pig thorax simulator. Online content including video sequences viewable at: https://www. thieme-connect.com/products/ejournals/html/ 10.1055/s-0040-1716859.

\section{Discussion}

Simulation is an integral part of surgical and microsurgical education as it provides a safe and controlled environment for the acquisition of skills prior to entering the OR. ${ }^{10}$ Formal incorporation of simulation in microsurgery training curric- ulum, however, is lacking, and trainees feel dry laboratory skill training with simulators is underutilized. ${ }^{11}$ Innovative training models have been created in many areas of microsurgery from microsurgical and supermicrosurgical anastomoses to harvesting of ALT flaps, but a model of internal mammary vessel dissection currently does not exist. ${ }^{7,12}$

The domestic pig is an animal model used frequently in medical research for its anatomic and metabolic similarity to humans. ${ }^{13-17}$ As a preclinical model, the importance of the domestic pig cannot be overstated. They are frequently used at academic institutions and thus are readily available. We have found it is easy to obtain cadaveric porcine chest walls at the termination of other studies on our campus, which is cost-effective and ethically supports the three Rs (replacement, reduction, and refinement) of animal research. ${ }^{18}$

The utility of live and cadaveric pig specimens as surgical training tools has shown to be effective in many instances, from kidney transplants to lymphaticovenular anastomoses. ${ }^{19-22}$ We have shown this similarity and potential as a surgical training model translates to the dissection of internal mammary vessels. Though there are some anatomic differences between the porcine thorax and the human thorax, as a whole, this simulator has good face validity and is well suited for training of plastic surgery residents for the preparation and anastomosis of the internal mammary vessels. Formal incorporation of this model into our program's microsurgery training curriculum has been well received. Resident and faculty perspectives on the realism and utility of the model will be published in a forthcoming study.

Further, based on the anatomical and geometric configuration of the rib spaces, with homologous anatomy and similar ICS width, the model is also suitable for practicing rib-sparing internal mammary isolation. ${ }^{23,24}$ Though the focus of this paper was on the more traditional nonrib-sparing technique to demonstrate feasibility of the swine thorax, the simulator is well suited for future studies on various methodologies of internal mammary isolation (rib-sparing vs. nonrib-sparing) and microsurgical anastomosis (loupe vs. microscope).

Overall, this model can be assembled quickly, at low cost, and allows for multiple training sessions per specimen. Residents are able to practice steps beyond microsurgical anastomosis, such as dissection to rib, incision and elevation of perichondrium, excision of rib, identification of vessels, end-to-end anastomosis of IMA, and use of venous coupler on IMV, all while working at a realistic depth. Augmentation of this model with a perfusion system creates a highly 
realistic simulation experience allowing for real-time feedback of anastomotic quality.

\section{Conclusion}

The blue-blood porcine chest wall model provides simple, inexpensive, and realistic simulation of IMA preparation and anastomosis. Training with this novel model can bridge the gap between existing basic microsurgical models and the OR for performing these key steps of autologous breast reconstruction.

\section{Conflict of Interest \\ None declared.}

\section{References}

1 American Society of Plastic Surgeons. 2018Plastic surgery statistics report. Available at: https://www.plasticsurgery.org/documents/News/Statistics/2018/reconstructive-procedure-trends-2018. pdf. Accessed February 29, 2020

2 Ilonzo N, Tsang A, Tsantes S, Estabrook A, Thu Ma AM. Breast reconstruction after mastectomy: a ten-year analysis of trends and immediate postoperative outcomes. Breast 2017;32:7-12

3 Moran SL, Nava G, Behnam AB, Serletti JM. An outcome analysis comparing the thoracodorsal and internal mammary vessels as recipient sites for microvascular breast reconstruction: a prospective study of 100 patients. Plast Reconstr Surg 2003;111(06): 1876-1882

4 Serletti JM, Moran SL. Microvascular reconstruction of the breast. Semin Surg Oncol 2000;19(03):264-271

5 Patel AJ, Malata CM. Intercostal drain insertion for pneumothorax following free flap breast reconstruction-a near miss!. J Plast Reconstr Aesthet Surg 2010;63(11):1929-1931

6 Shulzhenko NO, Zeng W, Albano NJ, et al. Multispecialty microsurgical course utilizing the blue-blood chicken thigh model significantly improves resident comfort, confidence, and attitudes in multiple domains. J Reconstr Microsurg 2020;36(02):142-150

7 Zeng W, Shulzhenko NO, Feldman CC, Dingle AM, Poore SO. "Blueblood"- infused chicken thigh training model for microsurgery and supermicrosurgery. Plast Reconstr Surg Glob Open 2018;6 (04):e1695

8 Cook JA, Tholpady SS, Momeni A, Chu MW. Predictors of internal mammary vessel diameter: a computed tomographic angiography-assisted anatomic analysis. J Plast Reconstr Aesthet Surg 2016;69(10):1340-1348

9 Lee CD, Butterworth J, Stephens RE, Wright B, Surek C. Location of the internal mammary vessels for microvascular autologous breast reconstruction: the "1-2-3 rule". Plast Reconstr Surg 2018;142(01):28-36

10 Evgeniou E, Walker H, Gujral S. The role of simulation in microsurgical education. J Surg Educ 2018;75(01):171-181

11 Sullivan BJ, Maliha S, Henderson PW. Microsurgery fellows impression of clinical and educational offerings during fellowship year. J Reconstr Microsurg 2020;36(03):191-196

12 Costa AL, Cucinotta F, Fazio A, et al. Anterolateral thigh flap in a chicken model: a novel perforator training model. J Reconstr Microsurg 2019;35(07):485-488

13 Renner S, Blutke A, Clauss S, et al. Porcine models for studying complications and organ crosstalk in diabetes mellitus. Cell Tissue Res 2020;380(02):341-378

14 Briceno N, Annamalai SK, Reyelt L, et al. Left ventricular unloading increases the coronary collateral flow index before reperfusion and reduces infarct size in a swine model of acute myocardial infarction. J Am Heart Assoc 2019;8(22):e013586

15 Aigner B, Renner S, Kessler B, et al. Transgenic pigs as models for translational biomedical research. J Mol Med (Berl) 2010;88(07): 653-664

16 Lunney JK. Advances in swine biomedical model genomics. Int J Biol Sci 2007;3(03):179-184

17 Judge EP, Hughes JM, Egan JJ, Maguire M, Molloy EL, O’Dea S. Anatomy and bronchoscopy of the porcine lung. A model for translational respiratory medicine. Am J Respir Cell Mol Biol 2014;51(03):334-343

18 Curzer HJ, Perry G, Wallace MC, Perry D. The three Rs of animal research: what they mean for the institutional animal care and use committee and why. Sci Eng Ethics 2016;22(02):549-565

19 Bartline PB, O'Shea J, McGreevy JM, Mueller MT. A novel perfused porcine simulator for teaching aortic anastomosis increases resident interest in vascular surgery. J Vasc Surg 2017;66(02): 642-648.e4

20 Peri L, Vilaseca A, Serapiao R, et al. Development of a pig model for laparoscopic kidney transplant. Exp Clin Transplant 2016;14(01): 22-26

21 Demertzis SD, Laschke MW, Siclari FPA, Menger MD. Non-robotic thoracoscopic internal mammary artery preparation in the pig. A training model. Interact Cardiovasc Thorac Surg 2008;7(04):556-559

22 Banda CH, Mitsui K, Ishiura R, Danno K, Narushima M. A supermicrosurgery pig foot training model for practice of lymphaticovenular anastomosis. Microsurgery 2020;40(01):91-92

23 Parrett BM, Caterson SA, Tobias AM, Lee BT. The rib-sparing technique for internal mammary vessel exposure in microsurgical breast reconstruction. Ann Plast Surg 2008;60(03):241-243

24 Wilson S, Weichman K, Broer PN, et al. To resect or not to resect: the effects of rib-sparing harvest of the internal mammary vessels in microsurgical breast reconstruction. J Reconstr Microsurg 2016;32(02):94-100 